\title{
The research and development of longitudinal profiled (LP) plate
}

\author{
Lu Shiping ${ }^{1,2}$, Li qun ${ }^{3}$, Wang Zhiyong ${ }^{3}$, Gu Linhao ${ }^{1,2}$, Zhang Xuanming $^{3}$ \\ ${ }^{1}$ Shougang Research\&Development Institute of Technology \\ ${ }^{2}$ Laboratory of Green Recyclable Process for Iron \& steel Production Technology \\ ${ }^{3}$ Shouqin Metal Materials CO.,LTD
}

\begin{abstract}
In this paper, the advantages of the longitudinal profiled(LP) steel plate is described, and the characteristics of LP plate rolling process is introduced. In contrast to the ordinary steel plate, The change rule of the bite angle and other parameters is put forward from the rolling principle. On this basis, the rolling plan is formulated. The finished condition of the steel plate is TMCP, and the size of the steel plate is corresponding to the setting value. Test result shows that the performance meets the standard of Q345. This indicates that LP plate has successfully developed in the Shougang thick plate plant.
\end{abstract}

\section{Backgroud}

In order to optimise the cross section structure of bridge, ship and building, under the premise of guarantee the strength and safety factor and reduce the length of weld steel and the weight, some steel corp in Japan and Europe have developed longitudinal profiled (LP)plate ${ }^{[1]}$. Compare with the traditional steel plate, LP plate is a kind of lightweight and saving steel. It has a broad market prospect.

\section{The theoretical research of LP plate}

The rolling process of LP plate can be divided into thickening and thinning rolling ${ }^{[2]}$. In the process of LP plate rolling, compare with the conventional rolling the exit position of the rolled piece has changed. During the conventional rolling process, the exit position of the rolled piece is located on the connecting line of the axle center of the two work rollers ${ }^{[3]}$. In the process of LP plate rolling, the exit of the thickening rolling is moved behind, and the exit of the thinning rolling is moved forward. The length of the contact arc in the thickening rolling is increase ,but it is decreased in the thinning rolling process. Figure1 and Figure 2 show the change in the exit position of the rolled piece during LP plate rolling process. Not only the exit of the rolled piece is changed, but also the change of the biting angle, the neutral angle, the front slide value, the length of the deformation zone and the average deformation speed of the rolling piece changed with time ${ }^{[4]}$. The bite angle of thickening rolling is less than that of ordinary rolling, and the bite angle of thinning rolling is greater than that of ordinary rolling, and the other parameters have similar change rules ${ }^{[5]}$. This will increase the instability of the rolling process.

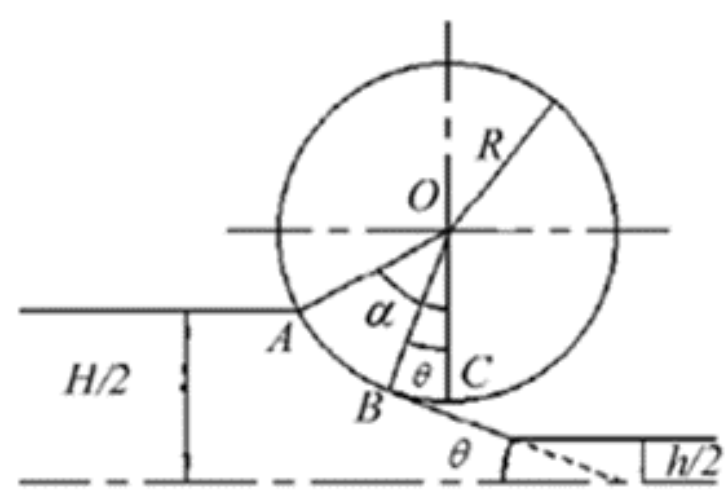

Figure 1. Thickening rolling process of LP plate

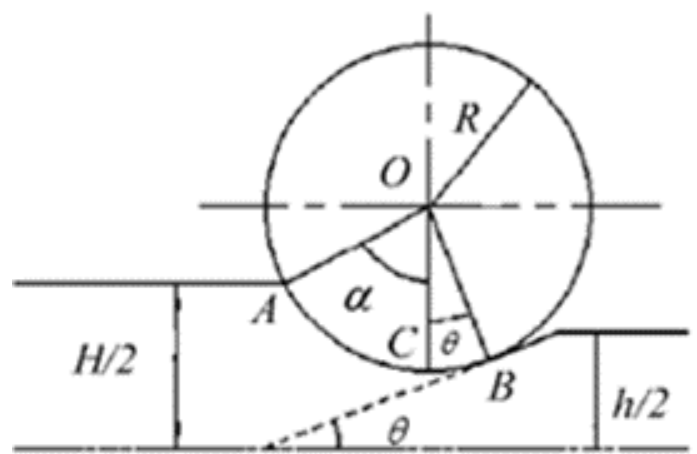

Figure 2. Thinning rolling process of LP plate

\section{The rolling plan of LP plate}

The chemical composition design of the steel plate as Table 1, the same as typical chemical composition of Q345. The designed size of the steel plate is three segments, the first section is constant at the thickness of $55 \mathrm{~mm}$, the length is $1 \mathrm{~m}$. The second section of the plate is continuous variable thickness. The thickness of the third segment is constant at $40 \mathrm{~mm}$, and the length is $1.5 \mathrm{~m}$.

* Corresponding author: lushiping@ shougang.com.cn 
Table 1. The alloy elements design

\begin{tabular}{ccccc}
\hline $\mathrm{C}$ & $\mathrm{Si}$ & $\mathrm{Mn}$ & $\mathrm{P}$ & $\mathrm{S}$ \\
\hline $0.14 \%$ & $0.3 \%$ & $1.4 \%$ & $0.01 \%$ & $0.004 \%$ \\
\hline
\end{tabular}

\section{The actual size and properties of steel}

\subsection{The size detection of LP plate}

After rolling, the data on both sides are manually measured. The actual rolling steel plate has a round head, and the actual measurement position starts from the rectangular position. There is size error between the operating side and the non operating side, but it can reflect the size change of the steel plate. The longitudinal thickness of the steel plate is changed shown as Figure 3. The parallel segment of the steel plate thickness is $55 \mathrm{~mm}$ and the length is 1.04 metre, and the thickness of $40 \mathrm{~mm}$ parallel segment is 1.4 metre. The length of the wedge section is about $7.7 \mathrm{~m}$. The actual cuneiform degree is $1.95 \mathrm{~mm} / \mathrm{m}$. The measured size shows as following Figure3.

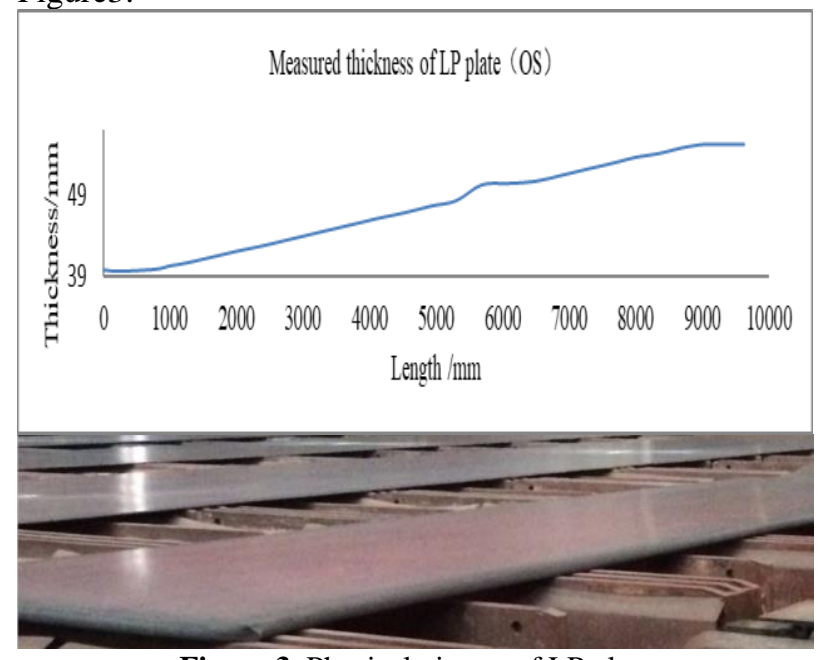

Figure 3. Physical picture of LP plate

\subsection{The Microstructure of LP plate}

Five sample location of the plate is set and the property test is taken, corresponding to different thickness. Remove the round head on the operation side,the position of $9305 \mathrm{~mm}$, the thickness $55.12 \mathrm{~mm}$ is LP1, the position of $6910 \mathrm{~mm}$, the thickness $51.42 \mathrm{~mm}$ is LP2, the position of $4120 \mathrm{~mm}$, the thickness $46.1 \mathrm{~mm}$ is LP3, the position of $1585 \mathrm{~mm}$, the thickness $41.3 \mathrm{~mm}$ is the LP4, the position of $180 \mathrm{~mm}$, the thickness is $39.65 \mathrm{~mm}$ is LP5. The microstructure shows as follow:

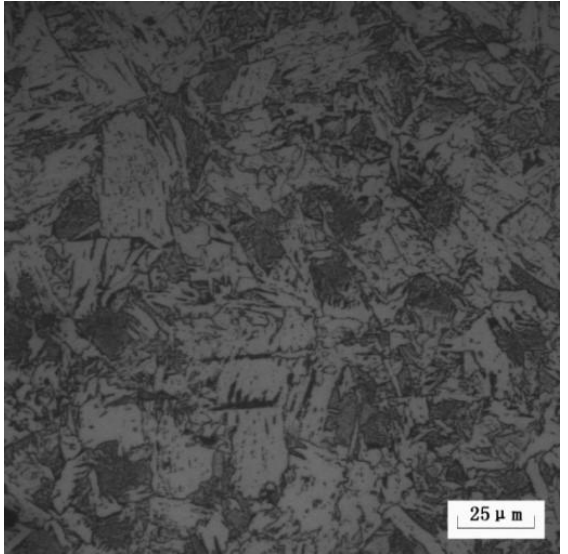

Figure 4. Microstructure of LP4.

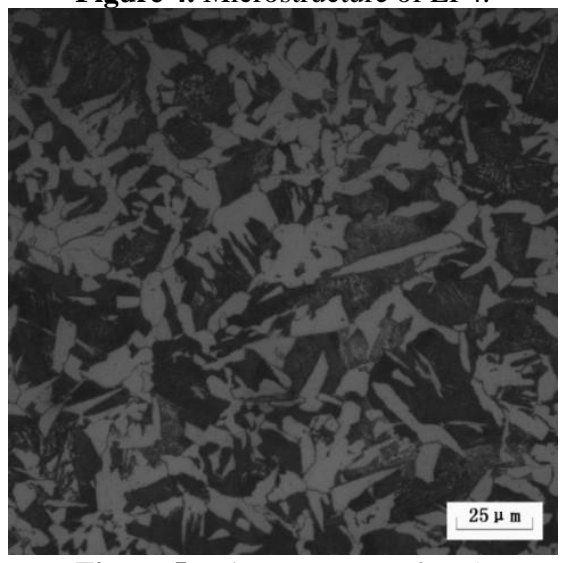

Figure 5. Microstructure of LP4.

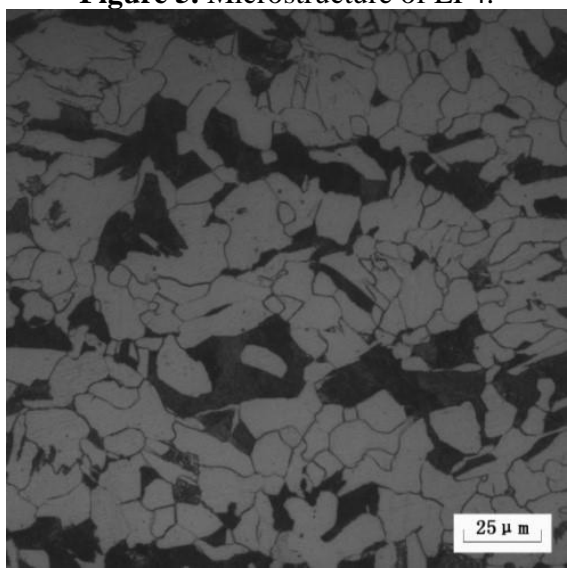

Figure 6. Microstructure of LP3.

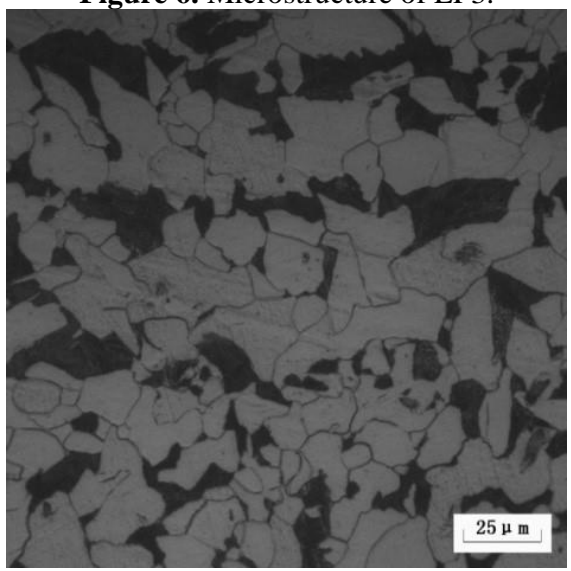

Figure 7. Microstructure of LP3. 


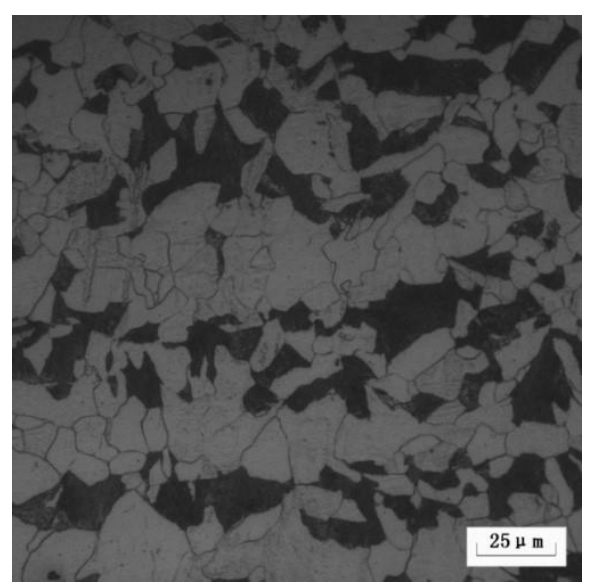

Figure 8. Microstructure of LP1.

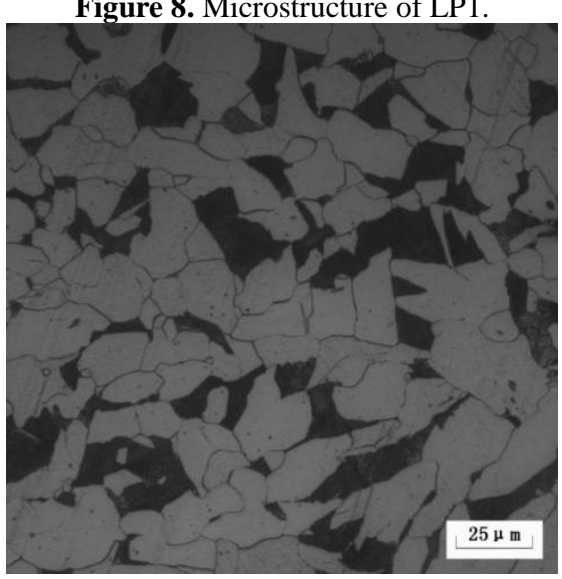

Figure 8. Microstructure of LP1.

It can be observed from the microstructure that the grain size from LP4 to LP1 become finer, which is related with the degree of deformation, also the relate the intensity of water cooling. The cooling stop temperature set as $650{ }^{\circ} \mathrm{C}$ at the thickness of $47.5 \mathrm{~mm}$, the final cooling temperature of LP5 part is much lower.The microstructure of LP5 to LP1 is also changed, from fine dispersed Ferrite to Quasi Polygonal Ferrite or Bulk Ferrite grain.The number of samples is less, and the corresponding intensity change rule is not obvious. The arrangement of the water cooling process parameters should refer to the microstructure, thickness setting standard forward or backward.

\subsection{The property of LP plate}

The mechanical properties is tested for several position corresponding to microstructure. With the increase of thickness, the general rule of yield strength gradually decreased, but all meet the standard requirements. The test result shows as Table2.

Table 2. The strength of LP plate

\begin{tabular}{cccccc}
\hline $\begin{array}{c}\text { Steel } \\
\text { grade }\end{array}$ & $\begin{array}{l}\text { Thicknes } \\
\text { s }\end{array}$ & $\begin{array}{c}\text { Sample } \\
\text { s }\end{array}$ & $\begin{array}{c}\text { Yiled } \\
\text { stress/M } \\
\mathrm{Pa}\end{array}$ & $\begin{array}{c}\text { Strenth/ } \\
\mathrm{MPa}\end{array}$ & $\begin{array}{c}\text { Absorbed } \\
\text { energy /J }\end{array}$ \\
\hline $\begin{array}{c}\mathbf{Q 3 4 5} \\
\mathbf{B}\end{array}$ & 55.1 & LP1 & 378 & 548 & 148 \\
$\begin{array}{c}\mathbf{Q 3 4 5} \\
\mathbf{B}\end{array}$ & 51.4 & LP2 & 357 & 540 & 149 \\
$\mathbf{Q 3 4 5}$ & 46.1 & LP3 & 367 & 539 & 133 \\
$\mathbf{B}$ & 4.1 & & & & \\
\hline
\end{tabular}

\begin{tabular}{cccccc}
\hline $\begin{array}{l}\text { Q345 } \\
\text { B }\end{array}$ & 41.3 & LP4 & 398 & 574 & 166 \\
\hline
\end{tabular}

\section{Conclusion}

In the process of LP plate rolling, the bite angle, neutral angle, front slip value, the length deformation zone and the average deformation velocity of metal vary with time.

LP plate has been developed successfully in Shougang thick plate plant. The steel is Q345, and the thickness range is $40-55 \mathrm{~mm}$.

Reasonable water cooling process should adopt in different position of length to minimize the fluctuation of the microstructure for the LP plate of TMCP.

Property test for different locations meet with the standard requirements of Q345.

\section{References}

1. Cui Zhongqi 1998 Principle of metallography and heat treatment(Haerbin: Harbin industrial university press) p302

2. Du Ping. Journal of longitudinal variable cross section rolling process $[\mathrm{J}]$. steel journal, 2008, 12 (12):26-29.

3. Osamu T, Takeshi K, Keniti A. Development of High Performance Steel Plates in terms of Reliability and Economy of Steel Structure[J]. Kawasaki Steel Giho, 2000, 32(3):198-204.

4. Du Ping.Research on the rolling theory and control strategy of longitudinal profiled plate [D]. Shenyang: Material processing engineering of Northeastern University.Doctoral dissertations, 2008.

5. Dong Lianchao.Metal felow law of longitudinally profiled flat sheet [D].Qinhuangdao:Yanshan University.Masters dissertations,2013. 